\title{
What we must learn from the US opioid epidemic
}

\author{
Fiona Godlee editor in chief
}

The BMJ

News flash: Donald Trump is doing the right thing. He looks set to declare America's epidemic of opioid misuse a national emergency. ${ }^{1}$ But the history of this epidemic is a masterclass in unintended consequences, and the big question now is what Trump and his administration choose to do next.

The scale of the epidemic is not in doubt. The US Centers for Disease Control and Prevention (CDC) reports that prescription and illicit opioid misuse caused more than 52000 deaths in 2015, a fourfold rise since $1999 .{ }^{2}$ But the seeds of the epidemic are complex, and the exact contribution of different events and players is disputed.

Most agree that it started in the 1990s, when doctors massively increased their prescribing of opioids for non-cancer pain, encouraged by drug companies' assurances that addiction was rare. This harmful overprescribing continues, write the pancreatic surgeon Martin Makary and colleagues this week (doi:10.1136/bmj.j4792). One in 16 surgery patients becomes a chronic opioid user, they say, and surgeons are the second highest opioid prescribers in the US after chronic pain specialists.

Surgeons vary widely in their prescribing behaviour and in their understanding of modern approaches to postoperative pain. This has to change, say Makary and colleagues, and so too must default settings on the number of pills prescribed: fewer tablets would limit stockpiling and reduce the risk of subsequent inappropriate use by patients and others, they say.

But we also publish a patient's plea not to demonise prescription opioids. Attributable deaths have fallen in recent years, says
Bob Roehr (doi:10.1136/bmj.j4727), who uses hydrocodone for back and joint pain and who disputes the CDC report's methodology. While most people who have become addicted began on prescribed opioids, only a tiny proportion progress to misusing them, he says. He blames the epidemic of deaths on the failure to provide addiction treatment for those who need it, driving them to increasingly available and cheap street heroin and, as Eugenia Socías and Evan Wood explained last month (doi:10.1136/bmj.j4355), to even cheaper and more deadly synthetic opioids such as fentanyl. Michael McCarthy reminds us that the well intentioned reformulation of oxycodone played its part, in driving intravenous users to heroin (doi:10.1136/bmj. j4730).

Our commentators agree on one thing: that the prohibitionist "war on drugs" mindset has done huge, perhaps the most, damage. In a time of economic decline and social fragmentation, such moralising and criminalising has blocked public health approaches that could have stemmed the tide of death and human misery (doi:10.1136/bmj.i6067). It is this above all that has to change.

1 Jacobs B. Trump says he'll declare the US opioid crisis a national emergency "next week." Guardian 16 Oct 2017. https:/www.theguardian.com/us-news/2017/oct/16/trump-usopioid-crisis-national-emergency.

Centers for Disease Control and Prevention. Annual surveillance report of drug related risks and outcomes. 2017. www.cdc.gov/drugoverdose/pdf/pubs/2017-cdc-drugsurveillance-report.pdf.

Published by the BMJ Publishing Group Limited. For permission to use (where not already granted under a licence) please go to http://group.bmj.com/group/rights-licensing/ permissions 